\title{
Effectiveness of Ringworm Cassia and Turmeric Plant Extracts on Growth Inhibition against Some Important Plant Pathogenic Fungi
}

\author{
Porntip Wongkaew ${ }^{1 *}$, Wantana Sinsiri ${ }^{2}$ \\ ${ }^{1}$ Plant pathology Division, Faculty of Agriculture, Khon Kaen University, Khon Kaen, Thailand \\ ${ }^{2}$ Department of Agricultural Technology, Faculty of Technology, Mahasarakham University, Mahasarakham, \\ Thailand \\ Email: ${ }^{*}$ Porwon@kku.ac.th
}

Received 6 December 2013; revised 6 February 2014; accepted 27 February 2014

Copyright (C) 2014 by authors and Scientific Research Publishing Inc.

This work is licensed under the Creative Commons Attribution International License (CC BY). http://creativecommons.org/licenses/by/4.0/

(c) $\underset{\mathrm{EY}}{0}$ Open Access

\begin{abstract}
Crude plant extracts of ringworm cassia, Cassia alata L. and turmeric, Curcuma longa L. were prepared by either hot water or organic solvents such as ethanol and ether. Various concentrations of the crude extract were then subjected to an in vitro test for their effectiveness on mycelia growth inhibition against some important plant pathogenic fungi such as Alternaria alternata, Colletotrichum gloeosporioides, Fusarium oxysporum fsp. lycopersici, Sclerotium rolfsii, Phytophthora infestans and Pythium sp. in comparison to commercial fungicides such as copper oxychloride and mancozeb. Reduction of the fungal growth was significantly obtained with $C$. longa extracts and the best median effective inhibitory concentration $\left(\mathrm{IC}_{50}\right)$ value of $6.07,6.50$ and $7.13 \mathrm{mg} / \mathrm{ml}$ was from the ethanol extract for $S$. rolfsii, $C$. gloeosporioides and $F$. oxysporum fsp. lycopersici respectively. While all extracts from $C$. alata were almost the least effective against these fungi. The efficacy of $C$. longa extracts therefore, provided an alternative regime for the control of the fungal diseases and a promising appreciable choice for a replacement of chemical fungicides.
\end{abstract}

\section{Keywords}

Crude Plant Extracts; Cassia alata; Curcuma longa; Commercial Fungicides; Plant Pathogenic Fungi; Commercial Fungicides; Mycelia Growth Inhibition

\footnotetext{
${ }^{*}$ Corresponding author.
}

How to cite this paper: Wongkaew, P. and Sinsiri, W. (2014) Effectiveness of Ringworm Cassia and Turmeric Plant Extracts on Growth Inhibition against Some Important Plant Pathogenic Fungi. American Journal of Plant Sciences, 5, 615-626. 


\section{Introduction}

The plant striking fungi as the tomato leaf spot fungus, Alternaria alternata, the anthracnose fungus Colletotrichum gloeosporioides, the tomato wilt fungus Fusarium oxysporum fsp. lycopersici, the crown and root rot fungus Sclerotium rolfsii, the tomato late blight fungus Phytophthora infestans and the crown and root rot fungus Pythium sp. are among major destructive pathogens that cause severe losses of economic crops throughout the world. It is estimated that about $20 \%-40 \%$ of the corresponding crop products are destroyed by these fungi [1]. Generally, the most common practice in controlling the plant pathogenic fungi is through the use of chemical fungicides. Although most of them are less toxic than most pesticides, they are, nevertheless, toxic substances. Many of them are not readily biodegradable and tend to persist for a long period in the area applied. They are also well known for their adverse genetic effects, causing morphological and physiological abnormalities in test animals that led to an indication for their deteriorating human health capability. In addition, they are considerably expensive for general farmers in developing countries. Moreover, the excessive use of fungicides has been clarified as a main factor causing the emergence of resistant strains that are uncontrollable. Development of an alternative material is thus, must be intensified to fulfill the growing demand for high quality antifungal agents, environment friendly and affordable practice.

Natural plant extract has been suggested to suit such demands due to their rich source of bioactive chemicals that often selectively active against specific target species and gradually biodegrade to nontoxic products. Ringworm cassia, Cassia alata L. and turmeric, Curcuma longa L. are the two well known tropical plants natively existing throughout Southeast Asia, Afirica, South America and Northern Australia. Both are traditionally accepted for their medicinal performance by local people since an old time. In Thailand, the C. alata is commonly grown as both ornamental and medicinal plant especially for a treat against ringworm and skin diseases, while the C. longa is household herbal plant cultivated for daily cooking and a universal traditional medicine [2]. The leaves of $C$. alata is found to be strong laxative, reduces inflammation, relieves pain, increases urination, perspiration, aids digestion, repels insects, kills bacteria, fungi, and other parasites. It has been reviewed that it contains many active substances such as alkaloids and flavonoids which directly activate the antimicrobial activity against pathogenic bacteria and fungi [2] [3]. The rhizome from C. longa L. has long been considered to reduce menstrual disorders, rheumatism and traumatic diseases, as well as to behave as antimicrobial, insecticidal repellent and anti-feeding against some stored-product insects. Its major active constituents are volatile oil and cucurminoids that posses the bio-protective properties including an antimicrobial activity [2] [4]. The extracts from C. alata and C. longa thus have long been realized for their successful antimicrobial activities against several foodborne and human pathogenic bacteria and fungi. Although they are rarely employed for plant disease therapy, but their capability in microbial growth inhibition is to be considered valid. As many features of fungal plant pathogens resemble those seen in animals and similar mechanisms have been observed during pathogenesis. While a similar processing of host defense responses such as signalling/signal transduction involve changes in protein phosphorylation, lipid metabolism and ion fluxes has been defined. While the resistance genes encoding specific receptors of pathogens have similar domains that are conserved in animals as well as the occurrences of several substrates and inhibitors during pathogenic invading in animals and plants that appear to be involved [5]. Due to these similarities, a satisfy activity of the plant extracts against plant pathogenic fungi would be reasonably obtained.

Therefore, to provide an alternative mean and a possibility in the development of new product to controlling these important plant pathogenic fungi, the growth inhibitory efficacy of C. alata leaf and C. longa rhizome extracts was investigated in vitro in comparison to the broad spectrum synthetic fungicides, copper oxychloride and mancozeb in this study.

\section{Materials and Methods}

\subsection{Fungal Isolates}

The virulent isolate of a tomato leaf spot fungus Alternaria alternate, a chilli pepper anthracnose fungus Colletotrichum gloeosporioides, a tomato wilt fungus Fusarium oxysporum fsp. lycopersici, a tomato crown and root rot fungus Sclerotium rolfsii, a tomato late blight fungus Phytophthora infestans and a seedling damping-off fungus Pythium sp. were collected from their corresponding infected host plant in the production fields at Nongkai Province, Northeastern Thailand. The obtained fungal isolates were identified according to their unique 
morphological and cultural characteristics as described by Barnett and Hunter in the year 1986 [6]. The pathogenicity of each was proven by repeat-inoculation on its host plant. Pure subcultures of these isolated fungi were then maintained on potato dextrose agar (PDA) medium at $4^{\circ} \mathrm{C}$ for further studies.

\subsection{Preparation of Plant Extracts}

Leaves of ringworm cassia, Cassia alata L. and rhizomes of turmeric, Curcuma longa L. were collected from medicinal plant garden farms at Mahasarkarm Province, Northeastern Thailand. They were specified and authenticated using relevant key and monographs [2]. In this experiment, the plant materials were extracted with the organic solvents i.e. ethanol and ether. Extraction by hot water was also performed in parallel. The selected parts of C. alata and C. longa were cleaned by several washing with running tap water following by distilled water. They were cut into small pieces and dried at room temperature for 15 days. Then the plant materials were grounded to fine powder in a grinder and subjected to the extraction solvents at a ratio of 2 kilograms per 10 liters for an extraction by maceration technique. These materials were left steeping in the selected solvent at room temperature for 48 hours with occasionally shaking. Afterward the consequent liquid including macerated materials were squeezed through double cheesecloth sheets, and filtered through a Whatman no. 1 filter paper to yield fresh extract solutions. Each extracted solution of an original 10 liters volume was concentrated with rotary vacuum evaporator at $50^{\circ} \mathrm{C}$ to obtain the final volume of $100 \mathrm{ml}$ and kept at $4^{\circ} \mathrm{C}$ prior to subsequent manipulations.

\subsection{Determination of Fungal Growth Inhibition Activity}

The Evaluation of plant extract performance was done by fungal mycelia growth assay on the culture medium containing a varied level of each plant extract. The final concentration included in PDA at 0, 1, 3, 5, 10, 30 and $50 \mathrm{mg} / \mathrm{ml}$ according to an original weight of the plant material in extraction solvent were tested for their action. The young-fungal isolates, A. alternata, C. gloeosporioides, F. oxysporum fsp. lycopersici, S. rolfsii, Ph. Infestans and Pythium sp. were prepared by mycelia transfer to new PDA medium. Then a subculture of each fungus at 5 days old was brought up for the test. A mycelia dish of $0.5 \mathrm{~cm}$ diameter was cut at the margin of their mycelia colony by sterilized stainless steel cork borer and placed at the center of the PDA amended with each of the test plant extract concentration. Commercial chemical fungicides such as copperoxychloride and mancozeb were chosen by their recommended trade for a comparison of the fungal inhibitory efficiency in this examination and each was used at similar concentration series. Evaluation of the fungal growth on the plant extracts amended PDA was done daily up to 14 days after cultured. All treatments were repeated at least 3 times with 5 replications. The percentage of mycelia growth inhibition was calculated following the equation: $\mathrm{Mi}=(\mathrm{Mc}-\mathrm{Mt}) / \mathrm{Mc} \times$ 100 , where Mi is the percent mycelia growth inhibition defined by colony diameter reduction, Mc is the colony diameter on the untreated PDA and Mt is the colony diameter on the treated PDA.

\subsection{Statistical Analysis}

Data were subjected to an analysis of variance and dosage response. The mean values were grouped for comparisons among treatments and the least significant differences among them at $P<0.05$ confidence level including the $\mathrm{IC}_{50}$ value or the concentration that inhibited $50 \%$ of the mycelia growth were calculated using SPSS statistics 17 software (2009 SPSS Inc., Chicago, Illinois 60606, USA.).

\section{Results}

\subsection{Variation among Potentiality of Plant Extracts}

The potentiality of crude extracts from C. alata and C. longa were investigated for their mycelia growth inhibition activity against six important plant pathogenic fungi, Alternaria alternata, Colletotrichum gloeosporioides, Fusarium oxysporum fsp. lycopersici, Sclerotium rolfsii, Phytophthora infestans and Pythium sp. Apparently, a variation of the activity has been executed among originated plants, solvent extraction systems and affected fungal species. Nevertheless, an inhibition level has tended to be dose dependent. As mycelium is the basis for fungal growth and represents the "body" of the fungus, the effect on mycelia growth of each fungus in the culture medium amended with each test crude extract and concentration was assumed by its colony diameter at 10 
days after incubation period. The growth inhibition percentage of each was then obtained in comparison to the fungal colony growth in normal PDA culture medium.

Growth of the tomato leaf spot fungus A. alternata on PDA amended with every type of $C$. alata crude extracts was indistinguishable from the normal profuse growth of this fungus on common PDA medium as well as on mancozeb fungicide treatment. Instead, a reduction on mycelia diameter and growth of this fungus was gained from the treatment with turmeric $C$. longa and copperoxychloride chemical with the inhibitory percentage around $52.52 \%-65.19 \%$ at $50 \mathrm{mg} / \mathrm{ml}$. (Figure 1). In case of the anthracnose fungus C. gloeosporioides, its mycelia diameter was slightly reduced on $C$ alata extracts with $35.93 \%-40.0 \%$ growth inhibition. While as much as $65.19 \%-73.33 \%$ mycelia growth inhibition with much less spore formation were obtained by the treat with C. longa extracts at this concentration and their response due to the extract dose was as shown in Figure 2. Similar effective pattern has also been activated against another two fungi, $F$. oxysporum fsp. lycopersici (Figure 3) and Sclerotium rolfsii (Figure 4) that the crude extracts of $C$. longa have showed an inhibition activity

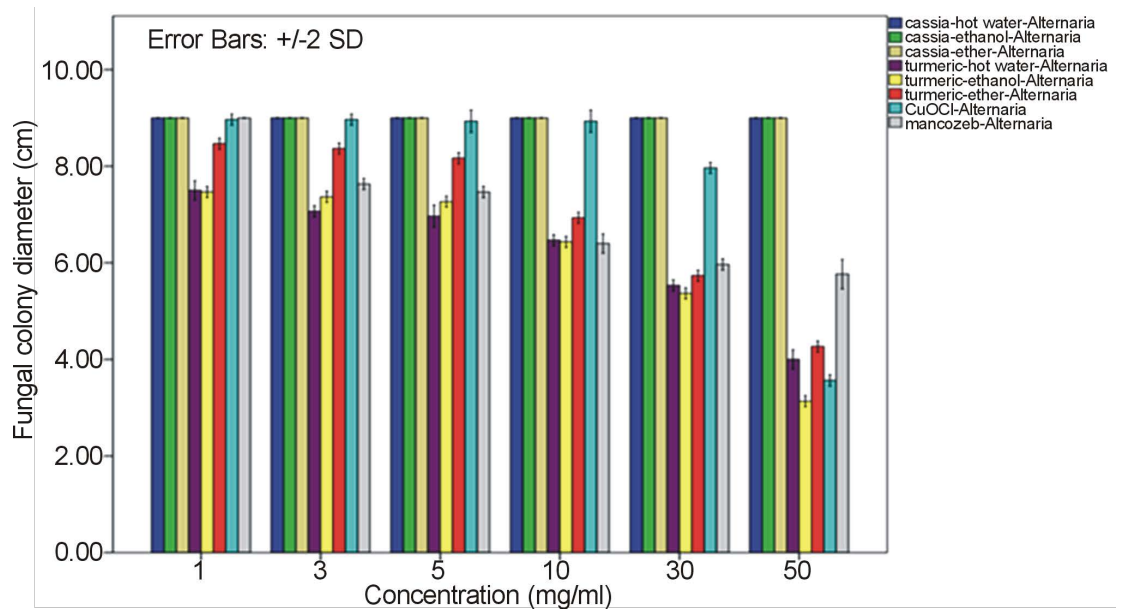

(a)

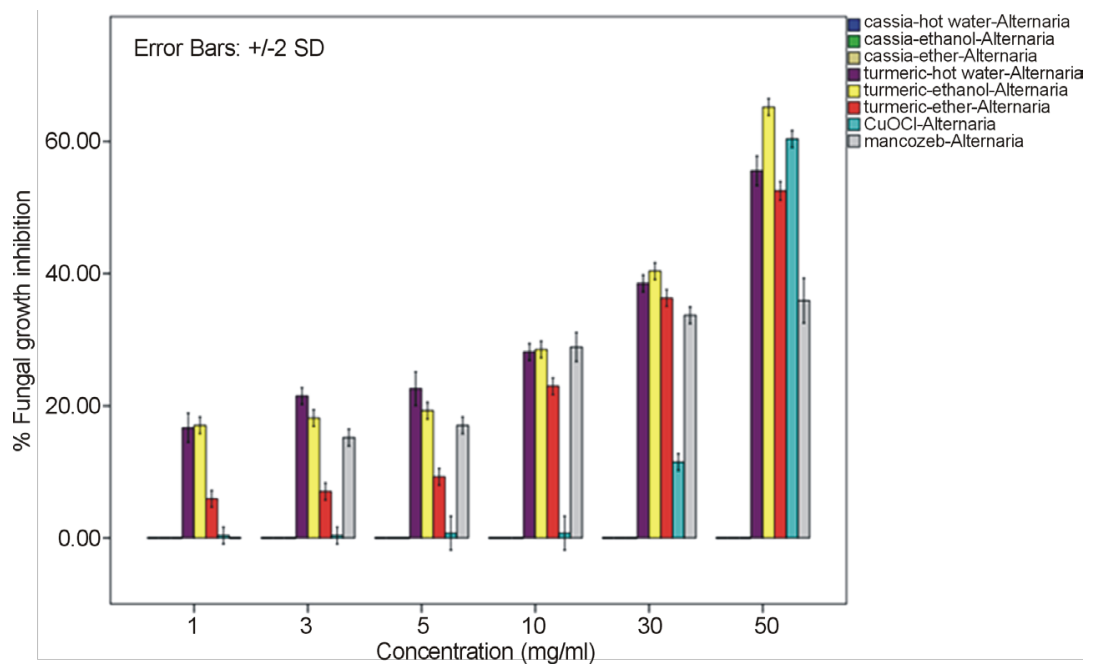

(b)

Figure 1. Effect of plant extracts on Alternaria alternata mycelia growth in comparison to chemical fungicides at the observed concentration (a = effect on mycelia growth evaluated by fungal colony diameter; $b$ = inhibition percentage of the fungal colony growth at the corresponding concentration). The column bars of each set in the graph represented response in the order of Cassia alata-hot water extract, C. alata-ethanol extract, C. alata-ether extract, Curcuma longa-hot water extract, C. longa-ethanol extract, $C$. longa-ether extract, copperoxychloride, and mancozeb, respectively. Reported values are in Arithmetic mean \pm Standard error. 


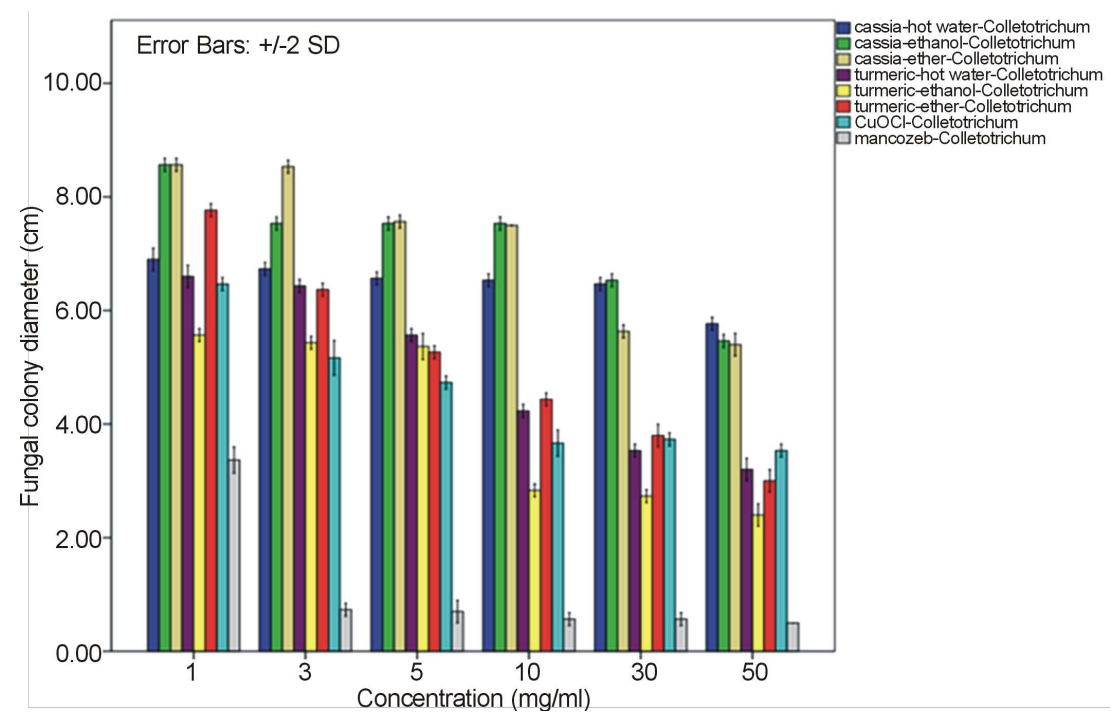

(a)

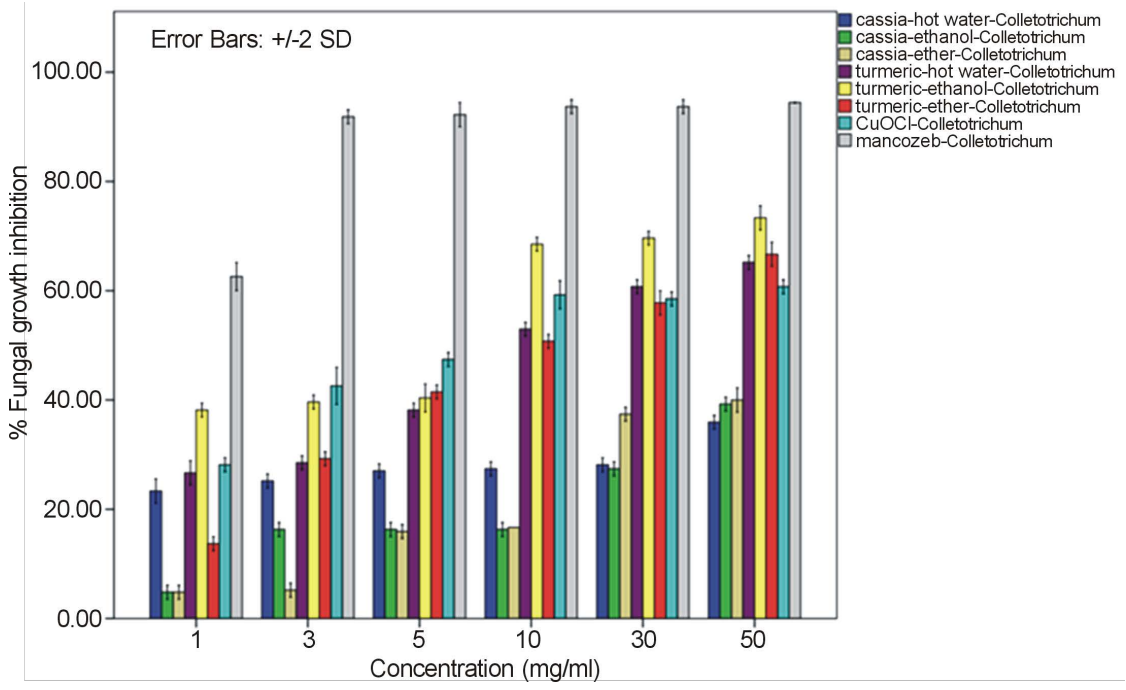

(b)

Figure 2. Effect of plant extracts on Colletotrichum gloeosporioides mycelia growth in comparison to chemical fungicides at the observed concentration ( $\mathrm{a}=$ effect on mycelia growth evaluated by fungal colony diameter; $b=$ inhibition percentage of the fungal colony growth at the corresponding concentration). The column bars of each set in the graph represented response in the order of Cassia alata-hot water extract, $C$. alata-ethanol extract, C. alata-ether extract, Curcuma longa-hot water extract, C. longa-ethanol extract, C. longa-ether extract, copperoxychloride, and mancozeb, respectively. Reported values are in Arithmetic mean \pm Standard error.

around $52.22 \%$ - 64.81\% and $60.74 \%$ - 78.52\% against F. oxysporum fsp. lycopersici and Sclerotium rolfsii respectively. In these cases, both the mycelia profile and spore mass were considerably much thinner than normal growth on PDA. No sclerotium granules formed at all in the test at high concentration of these $C$. longa extracts. While the crude extracts from C. alata has yielded only $17.04 \%-39.26 \%$ inhibition for $F$. oxysporum fsp. lycopersici and almost none for S..rolfsii. Evaluation of the plant extracts with two Oomycetes, Ph. infestans and Pythium sp. has presented a growth inhibition from $28.15 \%-50.37 \%$ by C. longa extracts and not at all by $C$. alata extracts (Figures 5 and 6). Although the efficacy on radius growth of these Oomycetes was quite low to median level but a noticeably huge reduction on mycelia dense was obviously seen following the treatment with C. longa extracts. Seemingly, the crude extract derived from ethanol solvent has aroused slightly better 


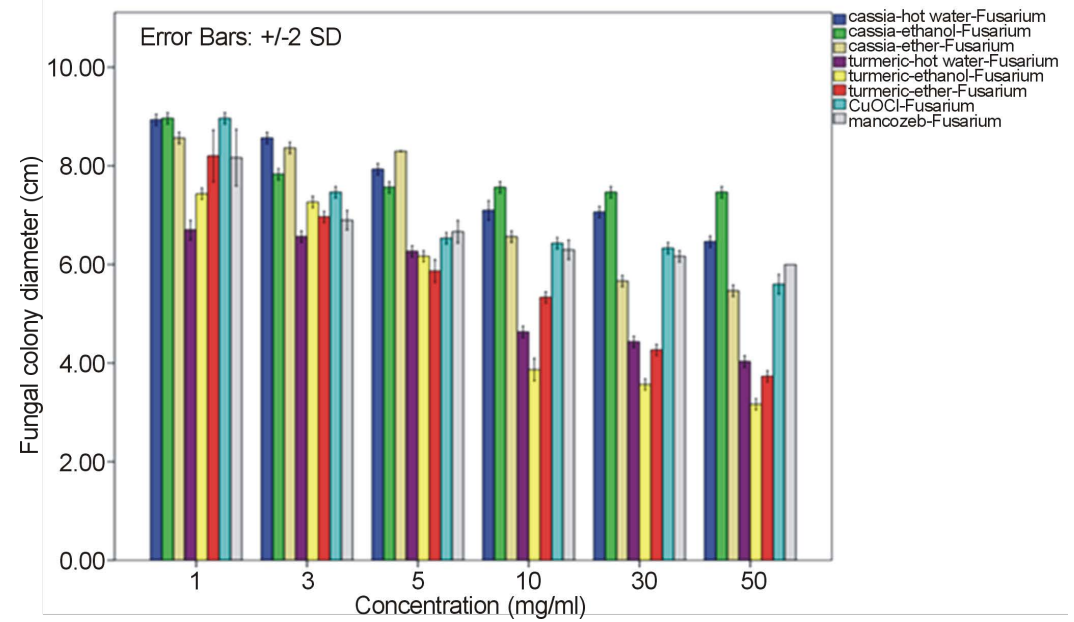

(a)

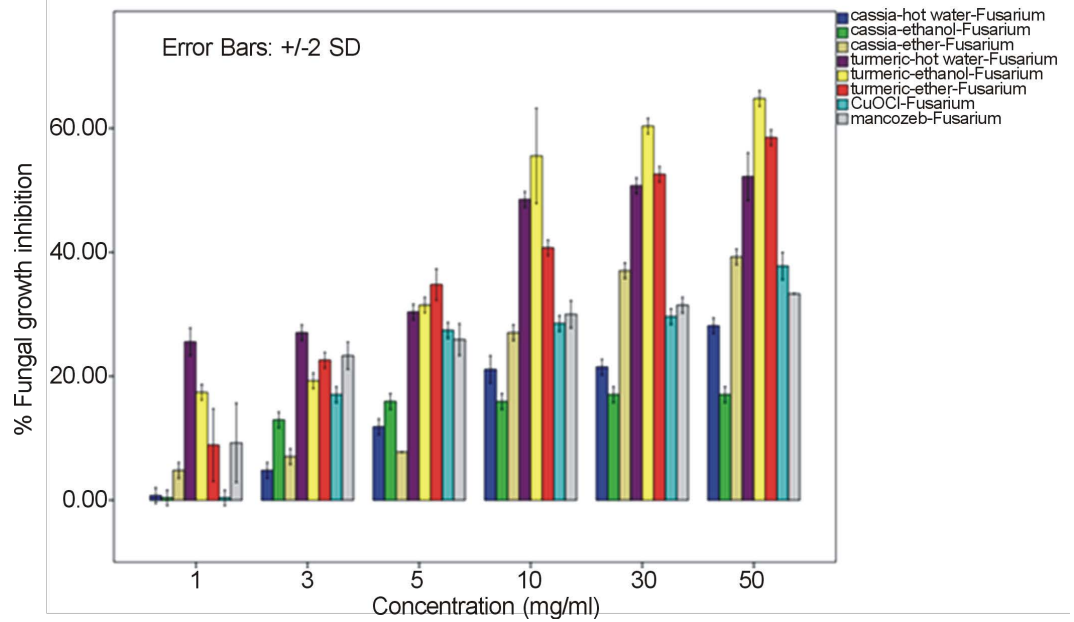

(b)

Figure 3. Effect of plant extracts on Fusarium oxysporum fsp. lycopersici mycelia growth in comparison to chemical fungicides at the observed concentration (a = effect on mycelia growth evaluated by fungal colony diameter; $b$ = inhibition percentage of the fungal colony growth at the corresponding concentration). The column bars of each set in the graph represented response in the order of Cassia alata-hot water extract, C. alata-ethanol extract, C. alata-ether extract, Curcuma longa-hot water extract, $C$. longa-ethanol extract, $C$. longa-ether extract, copperoxychloride, and mancozeb, respectively. Reported values are in Arithmetic mean \pm Standard error.

performance than those from hot water and ether solvent in these experiments. In the positive control test with commercial fungicides, a higher growth inhibition effect was appeared in the case of mancozeb with C. gloeosporioides, S. rolfsii, Ph. infestans and Pythium sp. as the growth of these fungi was almost completely inhibited by the concentration started from $3 \mathrm{mg} / \mathrm{ml}$. However, it was shown that the growth of A. alternata and $F$. oxysporum fsp. lycopersici was not effect by this fungicide. While the least effect on $F$. oxysporum fsp. lycopersici and S. rolfsii and some effective growth reduction on C. gloeosporioides, Ph. infestans and Pythium sp. were resulted from the treatment with copperoxychloride.

\subsection{Median Effective Inhibitory Concentration $\left(\mathrm{IC}_{50}\right)$ of the Plant Extracts}

The $\mathrm{IC}_{50}$ of investigated plant extracts against six plant pathogenic fungi was as categorized in Table 1 . All types of the extract from turmeric C. longa showed a high antifungal activity against C. gloeosporioides, 


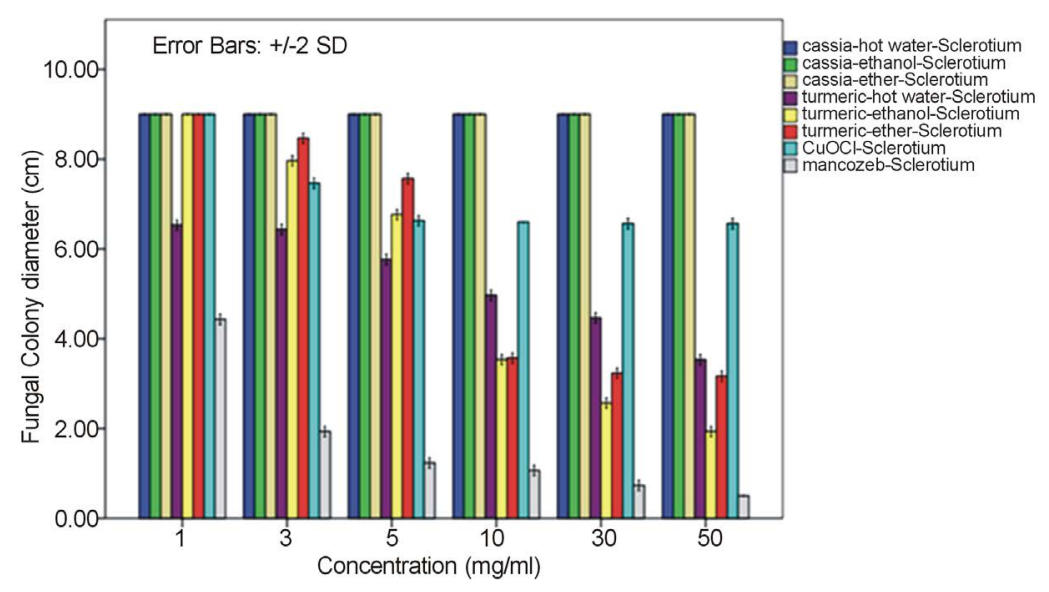

(a)

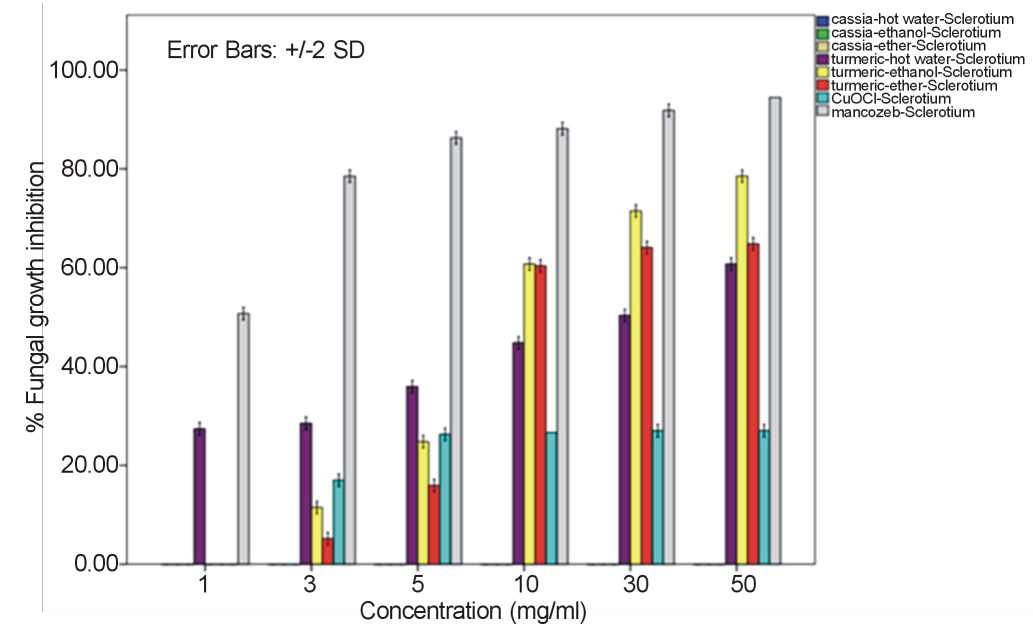

(b)

Figure 4. Effect of plant extracts on Sclerotium rolfsii mycelia growth in comparison to chemical fungicides at the observed concentration $(\mathrm{a}=$ effect on mycelia growth evaluated by fungal colony diameter; $b=$ inhibition percentage of the fungal colony growth at the corresponding concentration). The column bars of each set in the graph represented response in the order of Cassia alata-hot water extract, C. alata-ethanol extract, C. alata-ether extract, Curcuma longa-hot water extract, C. longa-ethanol extract, C. longa-ether extract, copperoxychloride, and mancozeb, respectively. Reported values are in Arithmetic mean \pm Standard error.

F. oxysporum fsp. lycopersici and S. rolfsii with a moderate action on A. alternata and a bit on Ph. infestans and Pythium sp. Among these, the best $\mathrm{IC}_{50}$ values such as $6.07,6.50$ and $7.13 \mathrm{mg} / \mathrm{ml}$ were obtained from C. longa ethanol extract for S. rolfsii, C. gloeosporioides and F. oxysporum fsp. lycopersici respectively. Whereas this values of the positive control copperoxychloride and mancozeb were $7.69 \mathrm{mg} / \mathrm{ml}$ and 0.87 respectively, for $C$. gloeosporioides. While the $C$. alata extracts had yielded ineffective results against the fungi except an ether-extract that the $\mathrm{IC}_{50}$ of 53.14 and $56.38 \mathrm{mg} / \mathrm{ml}$ was obtained for $C$. gloeosporioides and F. oxysporum fsp. lycopersici.

\section{Discussion}

Before The present investigation on an activity of cassia (Cassia alata) and turmeric (Curcuma longa) plant extracts has revealed a difference in their fungal constrictive efficacy against the selected plant pathogenic fungi such as Alternaria alternata, Colletotrichum gloeosporioides, Fusarium oxysporum fsp. lycopersici, Sclerotium rolfsii, Phytophthora infestans and Pythium sp. None of the extracts from C. alata yielded satisfactorily results 


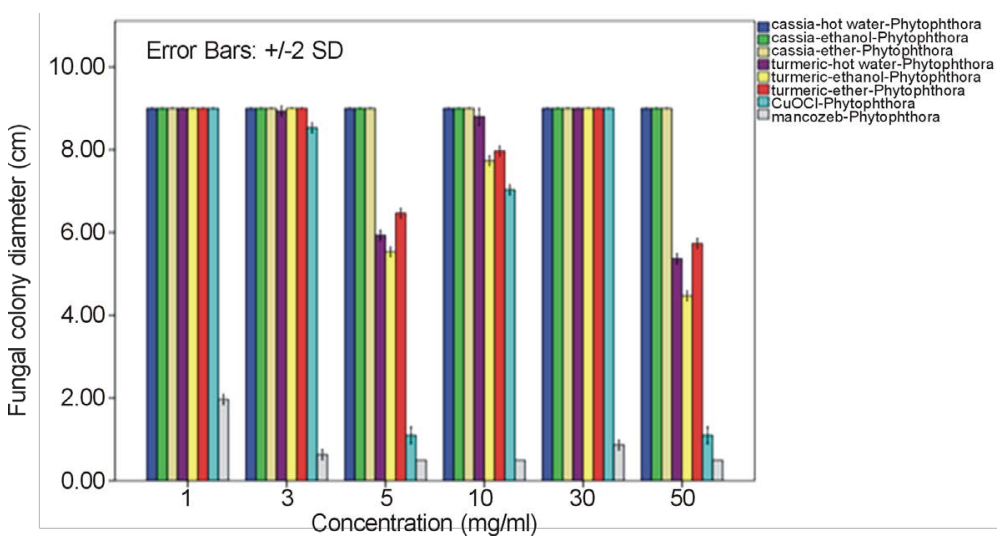

(a)

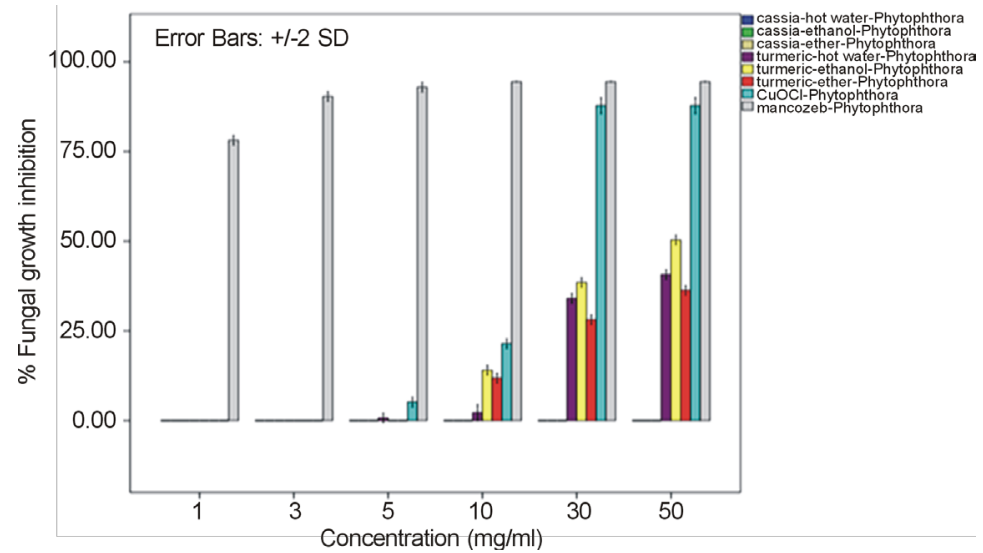

(b)

Figure 5. Effect of plant extracts on Phytophthora infestans mycelia growth in comparison to chemical fungicides at the observed concentration ( $\mathrm{a}=$ effect on mycelia growth evaluated by fungal colony diameter; $b=$ inhibition percentage of the fungal colony growth at the corresponding concentration). The column bars of each set in the graph represented response in the order of Cassia alata-hot water extract, C. alata-ethanol extract, C. alata-ether extract, Curcuma longa-hot water extract, C. longa-ethanol extract, C. longa-ether extract, copperoxychloride, and mancozeb, respectively. Reported values are in Arithmetic mean \pm Standard error.

Table 1. Median effective inhibitory concentration $\left(\mathrm{IC}_{50}\right)$ of investigated plant crude extracts against the selected plant pathogenic fungi in comparison to copperoxychloride and mancozeb fungicides.

\begin{tabular}{ccccccc}
\hline \multirow{2}{*}{ Treatments } & \multicolumn{5}{c}{ IC $_{50}(\mathrm{mg} / \mathrm{ml})^{*}$} \\
\cline { 2 - 7 } & $\begin{array}{c}\text { Alternaria } \\
\text { alternata }\end{array}$ & $\begin{array}{c}\text { Colletotrichum } \\
\text { gloeosporioides }\end{array}$ & $\begin{array}{c}\text { Fusarium oxysporum } \\
\text { fsp. lycopersici }\end{array}$ & $\begin{array}{c}\text { Sclerotium } \\
\text { rolfsii }\end{array}$ & $\begin{array}{c}\text { Phytophthora } \\
\text { infestans }\end{array}$ & $\begin{array}{c}\text { Pythium sp. } \\
\text { Cassia alata extracts v.i. } \\
\text { Hot water }\end{array}$ \\
Ethanol & - & - & - & - & - & - \\
Ether & - & $56.92 \pm 4.40$ & - & - & - & - \\
Curcuma longa extracts v.i. & - & $53.14 \pm 1.94$ & $56.38 \pm 4.40$ & - & - & - \\
Hot water & $40.13 \pm 1.07$ & $14.46 \pm 2.23$ & $32.42 \pm 6.76$ & $26.0 \pm 2.15$ & $56.14 \pm 1.29$ & - \\
Ethanol & $37.07 \pm 3.72$ & $6.50 \pm 2.6$ & $7.13 \pm 3.68$ & $6.07 \pm 0.55$ & $42.99 \pm 3.26$ & $56.92 \pm 2.04$ \\
Ether & $43.19 \pm 0.85$ & $15.87 \pm 2.35$ & $27.59 \pm 1.88$ & $17.63 \pm 2.33$ & - & - \\
Copperoxychloride & $46.06 \pm 0.05$ & $7.69 \pm 5.11$ & - & - & $15.09 \pm 0.4$ & $27.08 \pm 0.4$ \\
Mancozeb & - & $0.87 \pm 0.1$ & - & $1.40 \pm 0.22$ & $0.69 \pm 0.14$ & $0.68 \pm 0.17$ \\
\hline
\end{tabular}

*Antifungal activity at 10 days after mycelia cultured of the tested fungi on each treatment. 


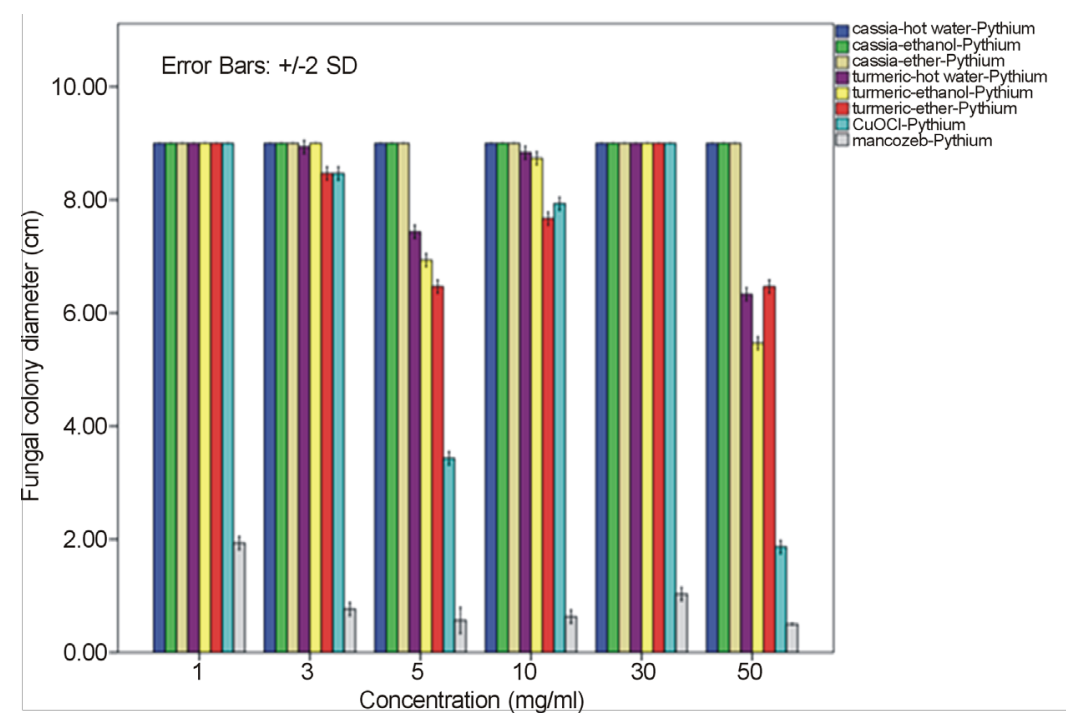

(a)

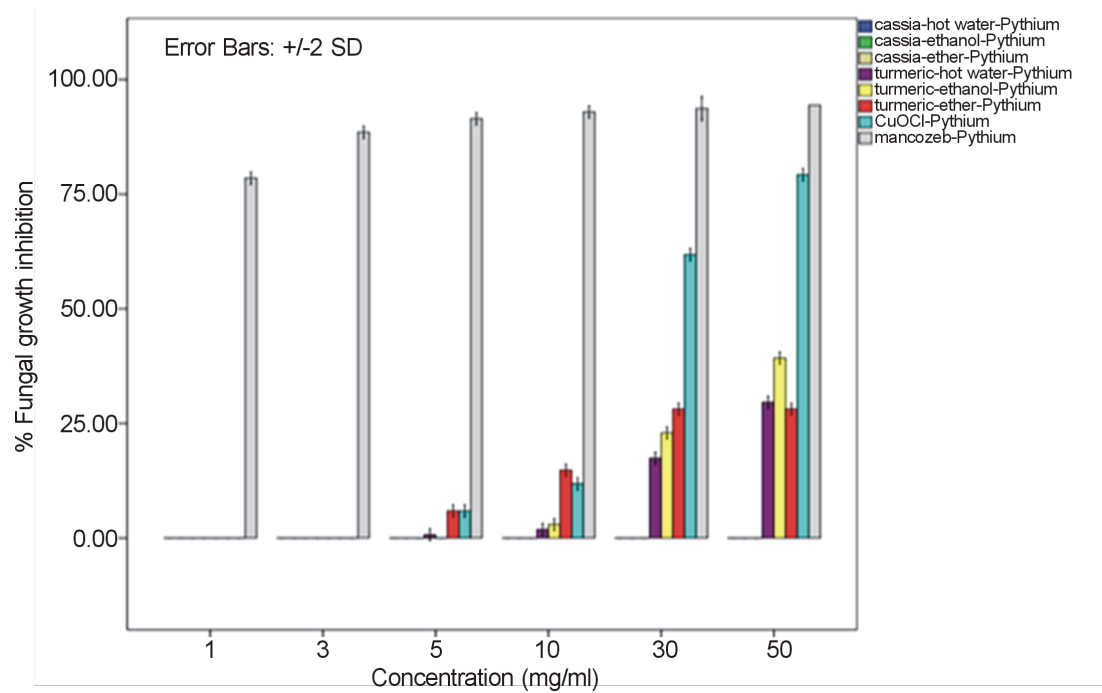

(b)

Figure 6. Effect of plant extracts on Pythium sp. mycelia growth in comparison to chemical fungicides at the observed concentration $(a=$ effect on mycelia growth evaluated by fungal colony diameter; $b=$ inhibition percentage of the fungal colony growth at the corresponding concentration). The column bars of each set in the graph represented response in the order of Cassia alata-hot water extract, C. alata-ethanol extract, C. alata-ether extract, Curcuma longa-hot water extract, C. longa-ethanol extract, C. longa-ether extract, copperoxychloride, and mancozeb, respectively. Reported values are in Arithmetic mean \pm Standard error.

against these fungi. A mycelia growth of A. alternata, Ph. Infestans and Pythium sp. was normally occurred and even more intensely occurred in the case of $S$. rolfsii with its profuse sclerotia. Nevertheless, a trend of growth restriction activity could be obtained from the ether-extract of $C$. alata with the test against $C$. gloeosporioides and $F$. oxysporum fsp. lycopersici, but it would need much higher concentration. Whereas much less effort could be gained from the test with turmeric $C$. longa extracts. It has been an indication by intensive phytochemical analysis that a main constituent of $C$. alata leaf extracts is flavonoid glycoside [7]. The flavonoid glycoside has been reported to possess great benefit to human health and exhibit inhibitory effect against many viruses and bacteria [8]. But it seems that there is no direct evidence for its stand alone effectiveness as antifungal activity [8]. A wide range of secondary metabolites such as anthraquinonse, saponin, alkaloids, steroids, and tannins as 
well as the flavonoid glycoside have been claimed to act in combination for antimicrobial properties. Leaf extracts from C. alata have shown a high antifungal activity against dermatophytes fungi such as Trichophyton, Microsporum, Epidermophyton and Candida and also some plant pathogenic fungi such as Aspergillus, Pennicillium, Rhizopus, and Mucor [7]-[11]. The More effective activity has been gained from aqueous extracts of $C$. alata flower against A. flavus, A. parasitica, Fusarium oxysporum, Helminthosporium oryzae, Candida albicans and Microsporum audouini [12]. However, the results from our experiment with C. alata extracts against another six plant pathogenic fungi were somehow contradictory to these reports. These might due to the difference among fungal species that are accountable for their specific interaction and counteraction with corresponding constituents in the crude extracts. It has also been observed that the crude extracts from C. alata contain large amount of polysaccharide such as galactomannan [13]. This type of polysaccharide and probably some other food additives might be responsible factors that favor the fungal growth ahead of an inhibitory effect from toxic constituents in C. alata extracts. Meanwhile, a variable degree of antifungal efficacy due to the capability of active constituent extraction against different fungi has been noticed among various solvents such as chloroform, ethanol, ether, ethyl acetate, hexane and methanol [7] [10] [11] [14]. A somehow higher activity of the ether extract of $C$. alata against $C$. gloeosporioides and $F$. oxysporum fsp. lycopersici thus could be seen in this investigation. However, it would need a huge cost and effort for traditional farmers to obtain the overweight active concentration by such extravagant organic solvent.

A broad spectrum of inhibition activity against the tested fungi was significantly displayed with the $C$. longa extracts particularly from the ethanol solvent system. The strongest efficacy was obtained with this $C$. longa ethanol extract against S. rolfsii, C. gloeosporioides, F. oxysporum fsp. lycopersici and A. alternata, respectively, although the inhibitory effect on growth of another two fungi, Ph. Infestans and Pythium sp. was not as much as expected. The antifungal efficiency could be comparable to copperoxychloride and mancozeb chemical fungicide that acted against $C$. gloeosporioides and much higher level in the case of A. alternata and F. oxysporum fsp. lycopersici. The inhibition efficacy of $C$. longa extracts was probably due to the presence of active constituents such as flavonoids, alkaloids, tannin, saponins, terpenes and some other phenolic compounds. Among these, the major compounds containing in the rhizome have been clarified to be aromatic oil turmerones and cucurminoids which possess an active antimicrobial feature [15] [16]. Crude extracts of $C$. longa rhizomes derived from various solvents have been demonstrated growth inhibition capability against a variety of pathogenic bacteria and fungi. In this study, the ethanol extract was shown to produce highest inhibitory effect against the tested fungi. An intensive study on the quality and quantity of active constituents yielded from organic solvent extraction has informed that the ethanol extract could provide higher percentage $(25 \%)$ of the yield than those from methanol, acetone and chloroform [17]. This conclusion thus could be claimed responsible for such effective results of the ethanol extract. A consistent efficacy of the ethanol extract has been achieved from a number of the test against an array of pathogens. Growth of many important hazardous bacteria has been shown to cease successfully by the ethanol extract in several reports such as Bacillus subtilis, Staphyloccocus aureus and Cryptococcus neoformans [18]; Vibrio harveyi, V. cholerae, V. alginolyticus, V. parahaemolyticus, V. vulnificus, Aeromonas hydrophila, Streptococcus agalactiae, Staph. aureus, Staph. epidermidis, Staph. intermidis, B. subtilis, B. cereus and Edwardsiella tarda [19]; Enterococcus faecalis and Staph. aurues [20]; B. subtillis, Staph. aureus, Escherichia coli and Staph. epidermitis [21]; Staph. aureus, B. subtilis and Pseudomonas aeruginosa [16]. The serious fungi such as Candida albicans and Aspergillus flavus have also been best inhibited by the ethanol extract [16] [18]. While the extract from methanol solvent has showed significant activity against the bacteria $B$. subtilis, Escherchia coli, stphaylocuccus aureus and pseudomonas fluorescence and the fungus Fusarium verticillioides [22]. On the other hand, reports on successful activity from an aqueous extract of $C$. longa rhizome have been displayed in consonance with our study. Growth inhibitory has been achieved against the bacteria $E$. coli, Staph. aureus, Krebsilla pneumonia and Staph. epidermidis, and Ent. faecalis [23] [24], and the fungi C. albicans and nine Candida species [24] [25].

In this present investigation with plant pathogenic fungi, none of the extracts from C. alata yielded satisfactorily result. However, a good performance could be exhibited by the extracts from the turmeric $C$. longa particularly against S. rolfsii, C. gloeosporioides, F. oxysporum fsp. lycopersici and A. alternata. The highest satisfaction was achieved in the $C$. longa-ethanol extract against $S$. rolfsii with an $\mathrm{IC}_{50}$ of 6.07 . These incidents therefore, provided a promising opportunity for a replacement of chemical fungicides. Since these plant extracts were shown sufficient antifungal efficacy and their preparation is quite simple. Although the highest activity was gained in the ethanol extract, extraction of active constituents by hot water and ether also yielded a marked inhi- 
bitory effect on the fungi, though with a bit smaller efficacy. Moreover, the considerable results from the $C$. longa-hot water extract could be chosen as a compatible method for the low capital farmers. Application of these extracts would be most suitable especially for the control of $S$. rolfsii and F. oxysporum fsp. lycopersici. As these two fungi are the soilborne pathogens that appear around the rhizosphere of their host plants, hence allows an easy application by soil drenching without any side effect on photosynthetic part of the plant from dark yellow pigments of the extracts. The results gained from this investigation particularly with the $C$. longa extracts, thus could provide a high possibility in the use of plant extract for a safer and cheaper control of infectious plant disease.

\section{Acknowledgements}

The authors are grateful to the Biosensing Technology for Sustaining Development Research Group of Khon Kaen University for their support and the Department of Agricultual Technology, Faculty of Technology, Mahasarakarm University for their technical assistance in part.

\section{References}

[1] Agrios, G.N. (2005) Plant Pathology. 5th Edition, Elsevier Academic Press, New York.

[2] Bunyaprapatr, N. and Chokchaichareonporn, O. (1996) Indigenous Medicinal Plants. Medicinal Plants Information Office, Mahidol University Press, Bangkok.

[3] Markinde, A.A., Igoli, J.O., Amal, L.T.A., Shaibu, S.J. and Garbal, A (2007) Antimicrobial Activity of Cassia alata. African Journal of Biotechnology, 6, 1509-1510.

[4] Akram, M., Uddini, S., Ahmed, A., Usmanghani, K., Hannan, A., Mohiuddin, E. and Asif, M. (2010) Curcuma longa and Curcumin: A Review article. Romanian Journal of Biology and Plant Biology, 55, 65-70.

[5] Collazo, C., Chacon, O. and Barras, O. (2006) Programmed cell death in plants and animals. Biotecnología Aplicada, 23, 1-10.

[6] Barnett, H.L. and Hunter, B.B. (1986) Illustrated Genera of Imperfect Fungi, 4th Edition. Macmillan Publishing Co., New York.

[7] Owoyale, J.A., Olatunji, G.A. and Oguntoye, S.O. (2005) Antifungal and Antibacterial Activities of an Alcoholic Extract of Senna alata Leaves. Journal of Applied Science and Environment, 9, 105-107.

[8] Sule, W.F., Okonko, I.O., Joseph, T.A., Ojezele, M.O., Nwanze, J.C., Alli, J.A., Adewale, O.G. and Ojezele, O.J. (2010) In-Vitro Antifungal Activity of Senna Alata Linn. Crude Leaf Extract. Research Journal of Biological Sciences, 5, 275-284. http://dx.doi.org/10.3923/rjbsci.2010.275.284

[9] Phongpaichit, S., Pujenjob, N., Rukachaisirikul, V. and Ongsakul, M. (2004) Antifungal Activity from Leaf Extracts of Cassia alata L., Cassia fistula L. and Caaaia tora L. Songklanakarin Journal of Science and technology, 26, 741-748.

[10] Doughari, J.H. and Okafor, B. (2007) Antimicrobial Activity of Senna alata Linn.. East and Central African Journal of Pharmaceutical Sciences, 10, 17-21.

[11] Timothy, M.S.Y., Wazis, C.H., Adati, R.G. and Maspalma, I.D. (2012) Antifungal Activity of Aqueous and Ethanolic Leaf Extracts of Cassia alata Linn. Journal of Applied Pharmaceutical Science, 2, 182-185.

[12] Abubacker, M.N., Ramanathan, R. and Kumar, T.S. (2008) In Vitro Antifungal Activity of Cassia alata Linn. Flower Extract. Natural Product Radiance, 7, 6-9.

[13] Gupta, D.S., Jann, B., Bajpai, K.S. and Sharma, S.C. (1987) Structure of Galactomannan from Cassia alata Seed. Carbohydrate Research, 162, 271-276. http://dx.doi.org/10.1016/0008-6215(87)80222-7

[14] Villasenor, I.M., Canlas, A.P., Pascua, M.P.I., Sabando, M.N. and Soliven, L.A.P. (2002) Bioactivity Studies on Cassia alata Linn. Leaf Extract. Phytotherapy Researches, 16, S93-S96. http://dx.doi.org/10.1002/ptr.768

[15] Singh, M R. P. and Jain, D.A. (2011) Evaluation of Antimicrobial Activity of Volatile Oil and Total Curcuminoids Extracted fromTurmeric. International Journal of ChemTech Research, 3, 1172-1178.

[16] Harit, J., Barapatre, A., Prajapati, M., Aadil, K. R. and Senapati, S. (2013) Antimicrobial Activity of Rhizome of Selected Curcuma Variety. International Journal of Life Sciences Biotechnology and Pharma Research, 2, 183-189.

[17] Sawant, R.S. and Godghate, A.G. (2013) Qualitative Phytochemical Screening of Rhizomes of Cucurma longa Linn. International Journal of Science, Environment and Technology, 2, 634-641.

[18] Ungphaiboon, S., Supavita, T., Singchangchai, P., Sungkarak, S., Rattanasuwan, P. and Itharat, A. (2005) Study on Antioxidant and Antimicrobial Activities of Turmeric Clear Liquid Soap for Wound Treatment of HIV Patients. Songklanakarin Journal of Science and Technology, 27, 569-578. 
[19] Lawhavinit, O., Kongkathip, N. and Kongkathip, B. (2010) Antimicrobial Activity of Curcuminoids from Curcuma longa L. on Pathogenic Bacteria of Shrimp and Chicken. Kasetsart Journal (Natural Science), 44, 364-371.

[20] Saleem, M., Daniel, B. and Murli, K. (2011) Antimicrobial Activity of three Different Rhizomes of Curcuma longa \& Curcuma aromatic on Uropathogens of Diabetic Patients. International Journal of Pharmacy and Pharmaceutical Sciences, 3, 273-279.

[21] Jamal, Q., Munir, S., Sherwani, S.K., Sualeh, M., Jabeen, U., Malik, M. and Hussain, M. (2013) Antibacterial Activity of Two Medicinal Plants: Withania somnifera and Curcuma longa. European Academic Research, 1, 1335-1345.

[22] Alavijeh, P. K., Alavijeh, P.K. and Sharma, D. (2012) A Study of Antimicrobial Activity of Few Medicinal Herbs. Asian Journal of Plant Science and Research, 2, 496-502.

[23] Niamsa, N. and Sittiwet, C. (2009) Antimicrobial Activity of Curcuma longa Aqueous Extract. Journal of Pharmacology and Toxicology, 4, 173-77. http://dx.doi.org/10.3923/jpt.2009.173.177

[24] Hegde, M.N., Shetty, S., Yelapure, M. and Patil, A. (2012) Evaluation of Antimicrobial Activity of Aqueous and Hydro-Alcoholic Curcuma Longa Extracts against Endodontic Pathogens. IOSR Journal of Pharmacy, 2, 192-198. http://dx.doi.org/10.9790/3013-0220192198

[25] Kumar, A., Bhatii, V., Kumar, A., Patil, S., Bhatia, V. and Kumar, A. (2011) Screening of Various Plant Extracts for Antifungal Activity against Candida Species. World Journal of Science and Technology, 1, 2231-2587. 